\title{
60 years of UK visibility measurements: impact of meteorology and atmospheric pollutants on visibility
}

\author{
Ajit Singh, William J. Bloss, and Francis D. Pope \\ School of Geography, Earth and Environmental Sciences, University of Birmingham, Birmingham, B15 2TT, UK \\ Correspondence to: Francis D. Pope (f.pope@bham.ac.uk)
}

Received: 16 August 2016 - Discussion started: 26 August 2016

Revised: 6 January 2017 - Accepted: 17 January 2017 - Published: 13 February 2017

\begin{abstract}
Reduced visibility is an indicator of poor air quality. Moreover, degradation in visibility can be hazardous to human safety; for example, low visibility can lead to road, rail, sea and air accidents. In this paper, we explore the combined influence of atmospheric aerosol particle and gas characteristics, and meteorology, on long-term visibility. We use visibility data from eight meteorological stations, situated in the UK, which have been running since the 1950s. The site locations include urban, rural and marine environments.

Most stations show a long-term trend of increasing visibility, which is indicative of reductions in air pollution, especially in urban areas. Additionally, the visibility at all sites shows a very clear dependence on relative humidity, indicating the importance of aerosol hygroscopicity on the ability of aerosol particles to scatter radiation. The dependence of visibility on other meteorological parameters, such as wind speed and wind direction, is also investigated. Most stations show long-term increases in temperature which can be ascribed to climate change, land-use changes (e.g. urban heat island effects) or a combination of both; the observed effect is greatest in urban areas. The impact of this temperature change upon local relative humidity is discussed.

To explain the long-term visibility trends and their dependence on meteorological conditions, the measured data were fitted to a newly developed light-extinction model to generate predictions of historic aerosol and gas scattering and absorbing properties. In general, an excellent fit was achieved between measured and modelled visibility for all eight sites. The model incorporates parameterizations of aerosol hygroscopicity, particle concentration, particle scattering, and particle and gas absorption. This new model should be applicable and is easily transferrable to other data sets worldwide. Hence, historical visibility data can be used to assess trends
\end{abstract}

in aerosol particle properties. This approach may help constrain global model simulations which attempt to generate aerosol fields for time periods when observational data are scarce or non-existent. Both the measured visibility and the modelled aerosol properties reported in this paper highlight the success of the UK's Clean Air Act, which was passed in 1956, in cleaning the atmosphere of visibility-reducing pollutants.

\section{Introduction}

The meteorological definition of visibility is the "distance at which the contrast of a given object with respect to its background is just equal to the contrast threshold of an observer" (WMO, 1992, 2015). In general, good visibility is a desirable feature of any geographical location, and its importance should not be neglected (Doyle and Dorling, 2002). Poor visibility ( $<2.0 \mathrm{~km}$; Founda et al., 2016) can affect the transportation of goods and people, whether it is by rail, road, sea or air. Low visibility can lead to accidents and thus is a concern for public safety. Tourism is often dependent on good visibility for appreciation of points of interest (Singh and Dey, 2012). For example a study at Grand Canyon Park in the USA has shown that visitor frequency in the park has reduced as visibility decreased (Trijonis et al., 1990).

Typically in cloud-free sky, visibility can vary from ca. 5 to $100 \mathrm{~km}$ dependent on atmospheric composition and conditions. Visibility is reduced by the interaction of light with atmospheric gases and aerosol particles which can absorb or scatter the light; consequently visibility is greatest within non-polluted, pristine atmospheres, other factors (e.g. meteorology) being equal. Many previous studies have investi- 
gated the link between atmospheric composition and visibility (Jinhuan and Liquan, 2000; Schichtel et al., 2001; Wu et al., 2005; Park et al., 2003, 2006; Yang et al., 2007; Tiwari et al., 2011; Founda et al., 2016; Cao et al., 2012; Watson and Chow, 2006). These investigations demonstrate that visibility is markedly influenced by the size, chemical composition and concentration of airborne particles. Reduced visibility is attributed mainly to high concentrations of aerosol particles, and, in general, scattering effects are the dominant visibilityreducing mechanism within the atmosphere. Within heavily polluted atmospheres, visibility can decrease rapidly due to the presence of aerosol particles (Husar et al., 1981). For example, during the 1952 London smog events visibility declined to a few metres due to high air pollution (caused by a rise in smoke and other pollutant concentrations in the atmosphere; Wilkins, 1954) as discussed in detail by Brimblecombe (1987). More recently, a study by Sati and Mohan (2014) also found sharp decreases in visibility due to increased particulate matter (PM) and $\mathrm{NO}_{2}$ concentrations during a smog event in November 2012 in Delhi, India. Similarly, Zhang et al. (2006) described the PM influence upon visibility reduction at Beijing, China. Festivals involving fireworks, which release aerosol particles upon detonation, are a good example of spatially and temporally localized pollution events which may lead to reduced visibility (Singh et al., 2015; Seidel and Birnbaum, 2015; Kong et al., 2015).

In addition to aerosol and gas concentrations and composition, specific meteorological conditions can also affect visibility (Sloane, 1983). There exists a body of literature on urban visibility studies which attempt to connect visibility with meteorological parameters (e.g. Hänel, 1972; Clarke et al., 1978; Lee, 1983, 1990; Haywood and Boucher, 2000). Whilst temperature $(T)$, relative humidity $(\mathrm{RH})$, wind speed $\left(w_{\mathrm{s}}\right)$ and wind direction $\left(w_{\mathrm{d}}\right)$ do not affect clear-sky visibility directly, they can influence the sources and sinks of the trace gases and aerosol particles in the atmosphere. For example, high wind speeds can re-suspend dust particles and generate sea spray aerosol particles. Windy conditions can also lead to a cleaning effect by replacing polluted air with cleaner air. Temperature can influence the production of secondary organic aerosol (SOA) particles, for example, via the chemical formation and partitioning between the gas and particle phase. RH not only affects the sources and sinks of gases and aerosols; it also directly influences the size and composition of aerosol particles. Nearly all atmospheric aerosol particles are hygroscopic to some degree; hence, their size is dependent upon the local RH. As RH increases, hygroscopic particles take up water, through absorption and adsorption, and grow in size, volume and weight. The addition of water also changes the overall particle composition. This typically lowers the mean refractive index of the particle since the refractive index of water is lower than other common aerosol components, such as minerals, organics, sulfates and nitrates (Harrison et al., 2004). Under high-humidity conditions, a high particle loading in the lower atmosphere can increase fog formation and thus severely reduce visibility (Tiwari et al., 2011). It has previously been shown that monthly variations in visibility are negatively correlated with RH (Singh and Dey, 2012). Other studies have shown how the RH effect on particle hygroscopic growth can influence visibility change (Liu et al., 2012). Thus, both PM loading and meteorological factors, such as relative humidity, are important for the assessment of the causes of visibility reduction. Other factors may also be important such as vegetation density, industrial development, urbanization and human population since these factors affect surface type and can effect aerosol deposition (Diederen et al., 1985).

In the last few years, worldwide interest in atmospheric visibility has grown, but few studies examine UK visibility. Previously, a long-term trend analysis of visibility was performed at eight UK weather stations between 1950 and 1997 by Doyle and Dorling (2002), where improved visibility was identified at most of the stations, mainly after 1973 due to oil crises and less consumption. Summer visibility trends for five different sites in London and southern England for the period of 1962-1979 were analysed by Lee (1983), and it was also found that a rise in visibility was observed at all sites. Gomez and Smith (1984) quantified the seasonal visibility trends at Oxford during 1926-1985 and observed a clear reduction in visibility from 1926 to 1944, a notable rise after World War II from 1944 to 1952 and another reduction from 1952 to 1966 (mainly in the summer season); the visibility improved again after 1966 in all seasons due to the reduction in aerosol concentration (Gomez and Smith, 1987). It is also found that, since the 1956 Clean Air Act, fog occurrence has declined at Oxford and nearby rural areas due to a drop in smoke concentration, urban heat island effect and other public activities (Gomez and Smith, 1984). Analyses by Lee (1985) in central Scotland for the period of 1962-1982 have mentioned the effect of the 1973 oil crisis on visibility and air quality, where a significant increase in visibility was shown primarily in urban areas due to a major reduction in sulfate aerosol concentration. A similar study on historical visibility trends at 22 different UK meteorological stations (includes urban, rural and marine areas) during 1962-1990 was performed by Lee (1994). A clear rise in visibility was identified at most of the sites due to reduction in coal and smoke emissions (Lee, 1994). Furthermore, a steady reduction in fog frequency with improved visibility correlated with decreased smoke pollution at Glasgow airport was noted (Harris and Smith, 1982). The correlation between various air pollutants (such as $\mathrm{NH}_{4}^{+}$ and non-marine pollutants $\mathrm{SO}_{4}^{2-}$ and $\mathrm{NO}_{3}^{-}$) and visibility in northwest England, UK, were also performed in the 1980s, where strong negative correlations were found between visibility and these pollutants (Colbeck and Harrison, 1984). At present, most UK urban cities are relatively polluted (Defra, 2011) compared to rural locations, with pollutant sources dominated by vehicular emissions (Colvile et al., 2001). The 1956 Clean Air Act led to general improvements in UK air 
quality; however, there still exist many negative effects of air quality on the UK population such as impaired human health (Defra, 2011; Harrison et al., 2015).

The present study investigates visibility in the UK focusing on eight specific sites. The same sites were previously investigated by Doyle and Dorling (2002), who presented long-term UK visibility trends for 1950-1997 and the dependence of the measured visibility on meteorological conditions. In this paper we build upon the work of Doyle and Dorling (2002) to analyse UK visibility trends from 1950 to 2013. Furthermore, we extend the analysis by investigating causes of the observed visibility trends; in particular we investigate the role of air pollutant concentrations in UK visibility. The outputs from this work help to explain historic visibility trends in the UK. A new model is also presented which can aid in future visibility prediction under different climate and pollution scenarios.

\section{Data}

Daily archived horizontal visibility data, defined as the visibility distance along a horizontal line at the earth's surface, were obtained from the British Atmospheric Data Centre (BADC), which is run by the UK's Natural Environment Research Council (www.badc.nerc.ac.uk). The archive contains visibility data, in addition to other relevant meteorological parameters, archived at an hourly time resolution. In addition to visibility, the following meteorological parameters were also utilized: RH; wind speed; wind direction; air temperature; rainfall; and present weather (PR) code, which provides further qualitative detail about the weather conditions. A description of the present weather codes is provided in the table (http://badc.nerc.ac.uk/data/ukmo-midas/ WH_Table.html) at www.badc.nerc.ac.uk. Unfortunately the use of present weather codes largely ceased with the introduction of automated meteorological stations, and insufficient PR codes were available after the year 1997. It is noted that if the present weather codes had been available they would have been useful to screen the data for rain or other precipitation events. Due to unavailability of present weather codes during the required study period (1950-2012), data filtration was done on the bases of RH limits instead of PR codes. Data were removed when the relative humidity reading was $>99 \%$, which is highly suggestive of rain or other precipitation events. Removal of data with $\mathrm{RH}>99 \%$ removes between 0.91 and $3.44 \%$ of the data, dependent on site location. Since the ability of visibility observers is affected by light levels, with greater difficulty encountered in night-time measurements (Lee, 1990), the daily data used for this study were all measured at 12 noon for all sites.

Meteorological data were collected for the eight UK stations which possess near-continuous time series data starting in the 1950s and continuing to the present day. The eight stations are Aldergrove, Heathrow, Ringway, Nottingham, Ply- mouth, Tiree, Leuchars and Waddington, and details of the stations are given in Table 1 and Fig. 1.

The visibility data sets are based on ground-based measurement using a variety of techniques. More details of visibility observations method are found in the UK Met Office Surface Data Users Guide (https://badc.nerc.ac.uk/data/ ukmo-midas/ukmo_guide.html). Until the late 1990s all visibility measurements were performed by a human observer. Subsequently data collection was automated using visibility sensors (visiometers). See Table S1 in the Supplement for details on measurement type used and dates of service.

There are advantages and disadvantages with both human observation and visiometers. Clearly from a manpower perspective, visiometers are preferred. Human observation provides a true measure of visibility since the observer is looking for objects located at a known distances away from their location; however, the visibility measurements are imprecise by nature since results can vary according to the contrast and illuminance thresholds (ability to discern and sensitivity to light, respectively) of the observer's eyes (WMO, 2008). Since human observation requires objects to observe, the measurement is quantized by the geographical spread of available objects; i.e. there is not a continuum of measurement locations. Consequently, human observations provide a lower limit to the actual visibility. Distances between objects to observe can be large especially at the longer distances measured $(>10 \mathrm{~km})$, which leads to reductions in accuracy at high visibility. At high elevation the visibility calculation can be different from that at the surface (Malm et al., 1981). Visiometers automatically measure the extinction of light over a small distance (typically ca. $1 \mathrm{~m}$ ) and from the measured extinction can estimate visibility. In particular automatic visibility measuring instruments consist of a light transmitter and receiver; the light extinction observed between the transmitter and receiver is then used to estimate the visibility (Jebson, 2008). These automated estimates of visibility are more objective and reproducible than human observation. However, since the visiometer only measures air local to the device, it can be much more affected by variations in local air quality. This is likely to be a more important consideration at urban meteorological sites, where air composition is more heterogeneous than at rural sites, due to the greater number of pollutant sources in urban areas.

The change from human to automatic measurement occurred at different times for the different sites (see Table S1). It is clear for most sites investigated that the changeover from manually observed to automatically measured data leads to step changes in the visibility reported; see Fig. 2 and further discussion in methodology section. This is unsurprising given the discussion above. In particular, clear deviations away from the long-term trend measured under human observation are observed at Aldergrove, Plymouth and Tiree stations once automation was introduced (see Table S1). After consultation with the UK Met Office it was noted that automated sensors can be unreliable during high-visibility 
Table 1. Study stations with area and length of data description

\begin{tabular}{llrlrr}
\hline No. & Station name & $\begin{array}{r}\text { Station code } \\
\text { (src id) }\end{array}$ & Area & $\begin{array}{r}\text { Period } \\
\begin{array}{r}\text { Length of data } \\
\text { (in years) }\end{array}\end{array}$ \\
\hline 1 & Aldergrove & 1450 & Urban (airport) & $1950-2012$ & 63 \\
2 & Heathrow & 708 & Urban (airport) & $1950-2012$ & 63 \\
3 & Ringway & 1135 & Urban (airport) & $1950-2004$ & 55 \\
4 & Nottingham & 556 & Urban & $1957-2012$ & 56 \\
5 & Plymouth & 1336 & Urban (near coastal area) & $1950-2012$ & 63 \\
6 & Tiree & 18974 & Rural (airport, near coastal area) & $1957-2012$ & 56 \\
7 & Leuchars & 235 & Rural (RAF, near coastal area) & $1957-2012$ & 56 \\
8 & Waddington & 384 & Rural (RAF, airport) & $1950-2012$ & 63 \\
\hline
\end{tabular}

* RAF stands for Royal Air Force.
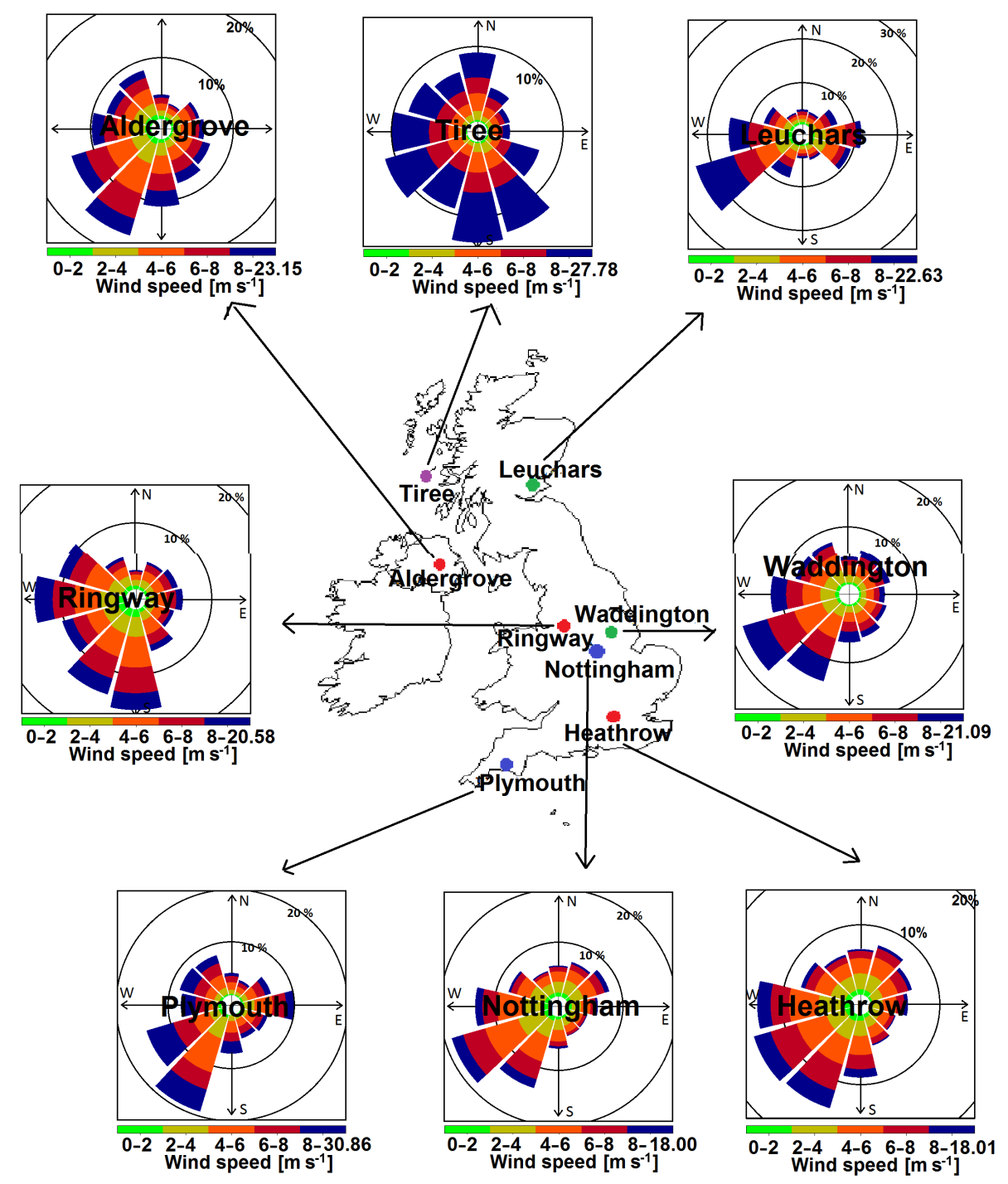

Figure 1. Geographical location of measurement stations used. Location point colours describe location type: red - urban airport; blue urban; purple - rural/remote; and green - rural airport. Also presented are mean wind rose statistics for the whole time period (approximately 60 years) for all eight stations. 
events when compared to human readings. In particular automatic sensors perform sub-optimally at coastal sites unless the sensor is cleaned regularly, due to accumulation of sea salt residue. Unfortunately, the Tiree station was reported to fall into this category.

To assess the effects of the gaseous pollutant nitrogen dioxide $\left(\mathrm{NO}_{2}\right)$ on visibility, daily ground-based measured data of $\mathrm{NO}_{2}$ were obtained from the Department of Environment Food and Rural Affairs (Defra) (https://uk-air.defra. gov.uk/) for one observing station (Harlington), closely colocated to the Heathrow meteorological station (ca. $2.1 \mathrm{~km}$ away). $\mathrm{NO}_{2}$ data were only available for 9 years (2004-2012) of the visibility study period.

\section{Methodology}

\subsection{Trend analysis of visibility and other meteorological parameters}

Sixty-year trend analyses have been performed on the visibility data set described in Sect. 2. For long-term trend analysis each day's value was averaged (simple mean) to determine trends over decadal, annual and seasonal cycles. The seasonal periods were defined, as is typical, as winter (December-February), spring (March-May), summer (JuneAugust) and autumn (September-November). Diurnal, dayof-the-week and monthly averaged trends of visibility and $\mathrm{RH}$ were determined at each site using the 60-year data set, where weekdays and weekend are categorized as MondayFriday and Saturday-Sunday, respectively.

To examine the hygroscopic growth effect of aerosol particles upon visibility, the decadal data sets were disaggregated into RH bins. The aerosol hygroscopic growth effect on visibility was examined by using decadal mean visibility within specific relative humidity bins with the following boundaries: $52.5-57.5,57.5-62.5,62.5-67.5,67.5-$ $72.5,72.5-77.5,77.5-82.5,82.5-87.5,87.5-92.5$ and $92.5-$ $97.5 \%$. We excluded data with RH $>97.5 \%$ due to the likely presence of fog and mist at RH greater than this threshold.

To highlight the daily variation in $\mathrm{RH}$, histograms of daily RH (at 12:00) were generated using the following boundaries: 0-10, 10-20, 20-30, 30-40, 40-50, 50-60, 60-70, 70$80,80-90$ and $90-100 \%$.

To evaluate the dominant meteorology at each site, several meteorological analyses were conducted. Wind rose plots using the complete data set time series were generated to highlight the dominant wind speed and direction for all sites. Decadal-seasonal bivariate polar plots of visibility using wind direction and wind speed allow for spatial analysis of likely pollution sources (Carslaw and Ropkins, 2012). Finally time series plots of the following meteorological parameters were generated: $\mathrm{RH}$, wind speed, wind direction and air temperature. These calculations were performed using the timePlot function in the openair package for the sta- tistical program $\mathrm{R}$, which works on vector functions for wind direction averaging.

\subsection{Estimation of aerosol and gas phase properties through analysis of RH-dependent visibility}

In this section the contribution of aerosol particles and gases to visibility is estimated via mathematical modelling. In general horizontal visibility $(V)$ can be defined via Koschmieder Eq. (1), where horizontal visibility shows an inverse relationship with the extinction coefficient $\left(\beta_{\text {ext }}\right)$. In Eq. (1), the constant $(k)$ is equal to 3.912, which assumes a contrast threshold of $2 \%$ (Koschmieder, 1924). The constant $(k)$ is a measured by the threshold sensitivity of the observer's eye (Schichtel et al., 2001; Chang et al., 2009), which can vary from 2 to $5 \%$ (Appel et al., 1985).

$V=k / \beta_{\text {ext }}$

The extinction coefficient depends upon $\left(\beta_{\text {ext }}\right)$ and is the sum of the scattering $\left(\beta_{\mathrm{sca}}\right)$ and absorption coefficients $\left(\beta_{\mathrm{abs}}\right)$ as shown in Eq. (2).

$\beta_{\mathrm{ext}}=\beta_{\mathrm{sca}}+\beta_{\mathrm{abs}}$

In the atmosphere, aerosol particles and gas phase species can contribute to both light scattering and absorption. However, the contribution of gas phase scattering to the total extinction is negligible except in the most pristine environments. Hence under UK conditions, the scattering component of the extinction coefficient can be assumed to be completely dominated by the presence of aerosol particles.

The ability of an individual particle to scatter radiation is dependent on its size, shape, morphology and refractive index (Appel et al., 1985; Liu and Daum, 2000). The particle scattering coefficient $\left(\beta_{\text {sca }}\right)$ can be estimated by Mie theory as shown in Eq. (1) (Tang, 1996);

$\beta_{\text {scat }}=\int_{0}^{\infty} \pi\left(\frac{D}{2}\right)^{2} Q_{\text {scat }}(\alpha, \lambda, n) N f(D) \mathrm{d} D$,

where $D$ represents particle diameter, the aerosol size distribution is given by $N f(D)$ and $\alpha$ is the size parameter $(\alpha=\pi D / \lambda) . N$ is particle number concentration, and $Q_{\text {scat }}(\alpha, \lambda, n)$ is single-particle scattering cross section, which depends upon size parameter $(\alpha)$, wavelength $(\lambda)$ and refractive index ( $n$, which is composition-dependent). All these particle characteristics can change as the particle undergoes water uptake or loss which is dependent on the local $\mathrm{RH}$. To parameterize the aerosol scattering enhancement due to water uptake, an approach similar to Titos et al. (2014) is taken. The scattering enhancement is parameterized using a single hygroscopicity parameter $(\gamma)$ using Eq. (4), where $\beta_{\text {sca }}(\mathrm{RH})$ and $\beta_{\text {sca }}$ (dry) are the aerosol scattering coefficients 
under specified RH conditions and completely dry conditions, respectively.

$$
\frac{\beta_{\text {sca }}(\mathrm{RH})}{\beta_{\text {sca }}(\text { dry })}=\left(1-\frac{\mathrm{RH}}{100}\right)^{-\gamma}
$$

Rearranging Eqs. (1), (2) and (4) allows for the relationship in Eq. (5) to be derived, where $\beta_{\text {abs }}(\mathrm{RH})$ and $\beta_{\text {abs }}$ (dry) are the combined aerosol and gas absorption coefficients under specified RH conditions and completely dry conditions, respectively.

$$
\operatorname{Vis}(\mathrm{RH})=\frac{3.912}{\left(1-\frac{\mathrm{RH}}{100}\right)^{-\gamma} \times\left(\frac{3.912}{\operatorname{Vis}(\mathrm{dry})}-\beta_{\mathrm{abs}(\mathrm{dry})}\right)+\beta_{\mathrm{abs}(\mathrm{RH})}}
$$

To reduce the number of parameters within Eq. (5), it is assumed that $\beta_{\text {abs }}(\mathrm{RH})=\beta_{\text {abs }}($ dry $)$. This assumption always holds for gas absorption, and it is largely true for aerosol particles as well, although it is noted that particle absorption can increase due to lensing effects in mixed-phase aerosol, and this lensing effect will be affected by aerosol water content (e.g. Lack and Cappa, 2010).

Equation (5) can be further simplified by assuming that all absorption due to both gases and particles is negligible compared to the RH-dependent aerosol scattering, leading to the two-parameter Eq. (6).

$$
\log [\operatorname{Vis}(\mathrm{RH})]=\gamma \log \left[1-\left(\frac{\mathrm{RH}}{100}\right)\right]+\log [\operatorname{Vis}(\text { dry })]
$$

Equations (5) and (6) can be used to obtain information about aerosol scattering and gas and aerosol absorption, with associated assumptions, through fitting of the measured visibility at a given RH. Equation (6) is linear and so can be fitted using the linear least-squares fitting algorithm, whereas Eq. (5) requires a non-linear least-squares fitting algorithm. The statistical program $\mathrm{R}$ was used for all fittings (Version 0.99.489). The "lm" algorithm was used for linear fitting, and the "nls" fitting algorithm was used for the non-linear fitting. The nls algorithm was always initially run with no lower or upper boundaries for the three fitting parameters (Vis(dry), $\beta_{\text {abs }}$ and $\gamma)$ specified. However, when fits produced negative values for $\beta_{\text {abs }}$, which are physically impossible, a lower boundary for $\beta_{\mathrm{abs}}$ was specified to be zero.

\subsection{Gas absorption}

All gases scatter radiation via Rayleigh scattering, but the effect is negligible in all but the most pristine visibility conditions (which are not observed in this study). The only atmospheric gas present at levels that lead to significant absorption of visible light is $\mathrm{NO}_{2}$ (Ferman et al., 1981; Groblicki et al., 1981). The contribution of $\mathrm{NO}_{2}$ to visibility can be quantified by its absorption coefficient $\left(\beta_{\mathrm{NO}_{2}}\right.$ abs $)$. The effect of the $\mathrm{NO}_{2}$ absorption coefficient, at $550 \mathrm{~nm}$ wavelength, was calculated using the relationship from Groblicki et al. (1981), shown in Eq. (7), where $\left[\mathrm{NO}_{2}\right]$ is the $\mathrm{NO}_{2}$ in parts per million (ppm).

$\beta_{\mathrm{NO}_{2} \text { abs }}=3.3 \times 10^{-4}\left[\mathrm{NO}_{2}\right]$

\section{Results and discussion}

\subsection{Historical trend of annual and seasonal visibility}

The annual and seasonal mean visibility at 12:00 have been calculated for all eight stations; see Fig. 2. The effect of changing the visibility observation technique from human observation to automatic observation via visiometers (which is highlighted by different shading in Fig. 2) is very clear at some sites. In particular, two stations, Tiree and Aldergrove, do not show realistic values after the changeover from human to automated measurement, with the changeovers coinciding with large and sustained drops in recorded visibility. The effect of human-to-automated-measurement changeovers at Heathrow, Leuchars, Nottingham, Ringway and Waddington sites appears to be minimal, with the pre-changeover long-term trends being continued after the changeover. Furthermore the annual data from these sites exhibit similar year-to-year variance before and after changeover. The longterm trend at the Plymouth site is similar before and after changeover, but the year-to-year variance is much reduced once measurement automation is installed. This likely indicates strong localized sources (ship and traffic emissions from nearby ports and roads) close to the visiometer at the Plymouth site. Henceforth it is assumed that all stations except Aldergrove and Tiree are performing adequately for both human and automated visibility measurement. Therefore the time series, as shown in Fig. 2, are used in their entirety for the analysis of these six stations. The time series data for the Aldergrove and Tiree stations are used up until automation occurs.

A similar variation in visibility trends is observed for the period of 1950-1997 to that in Doyle and Dorling (2002). However, this study reports overall lower visibility values than Doyle and Dorling (2002). These differences are due to slightly different data filtering methodologies. Doyle and Dorling (2002) filtered data for 12:00, relative humidity $>90 \%$ and PR codes of 00-05 in their statistical analysis for the period of 1950-1997. However, due to uncertainty and unavailability of PR code after 1997 we did not use these codes. Furthermore we performed mean averaging for statistical analysis, where data are filtered for 12 noon and relative humidity $>99 \%$. The details of uncertainty and unavailability of PR codes and the used data filtration method are given in the Data and Methodology sections.

Clear trends of increasing annual visibility are observed for four sites: Ringway, Waddington, Nottingham and Heathrow, with the rate of visibility increase being 

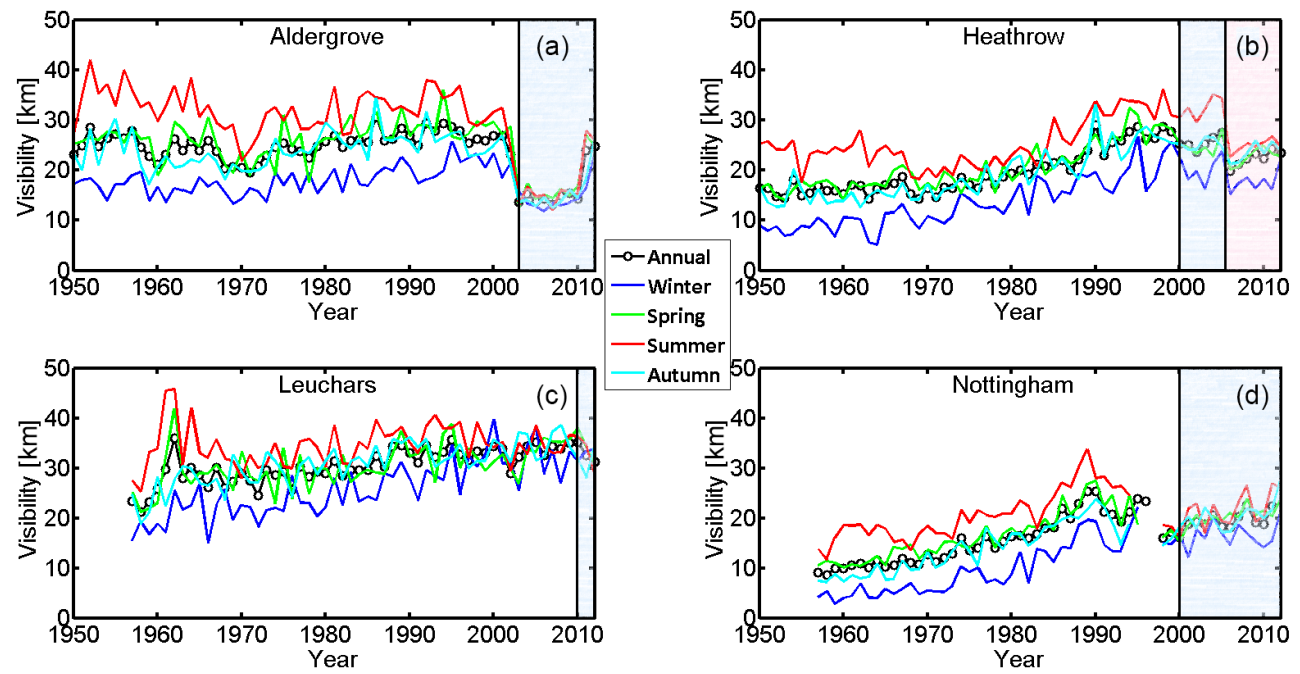

Summer
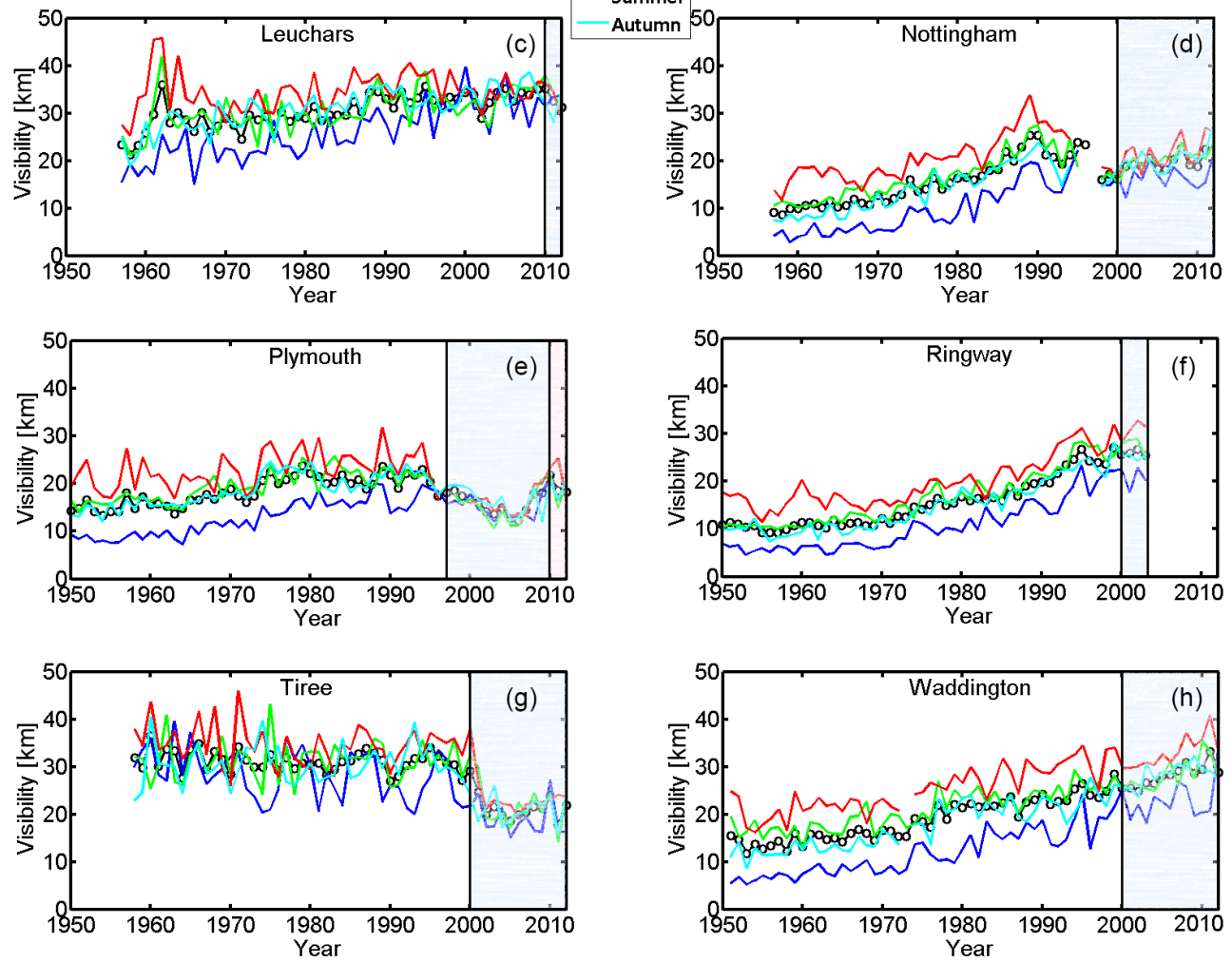

Figure 2. Historical trend of annual and seasonal visibility derived from daily (12:00) observations by station: (a) Aldergrove (b) Heathrow, (c) Leuchars, (d) Nottingham, (e) Plymouth, (f) Ringway, (g) Tiree, (h) Waddington. Shading indicates changes in measurement methodology, where white is human observation, while blue and red are automated observation using different instruments. For further details see Table S1.

$0.339 \pm 0.016,0.293 \pm 0.010,0.235 \pm 0.023$ and $0.201 \pm$ $0.018 \mathrm{~km}$ year $^{-1}$, respectively, where standard errors were determined at the $95 \%$ confidence interval. A, more gradual increasing trend was observed at the Leuchars site $\left(0.157 \pm 0.019 \mathrm{~km} \mathrm{year}^{-1}\right)$. The Plymouth site shows a more variable trend with increases from ca. 1950 to 1990 followed by decreases from ca. 1990 to 2006, which is then followed by more increases in the most recent measurements. The long-term trend for Plymouth in the period 19502013 is near constant $\left(0.040 \pm 0.021 \mathrm{kmyear}^{-1}\right)$. Both the Aldergrove and Tiree sites, with the automated data omitted, show near-constant long-term visibility with long-term rates of visibility change calculated to be $0.0562 \pm 0.021$ and $-0.0892 \pm 0.014 \mathrm{~km}$ year $^{-1}$, respectively.
The seasonal trends for the eight sites are detailed in Table 2. Poorest visibility was observed in the winter season compared to other seasons mostly due to the seasonal rise in RH (discussed in Sect. 4.3). Another reason is the greater concentration of particles in the environment due to lower mixing-layer height in the winter season (Jayamurugan et al., 2013). Furthermore, the long-term rate of visibility change in the winter season is significantly higher than in the spring, summer and autumn seasons for all stations apart from the Ringway station. At Ringway station the rate of change of visibility is higher in spring $\left(0.363 \pm 0.018 \mathrm{kmyear}^{-1}\right)$ than in winter $\left(0.330 \pm 0.020 \mathrm{kmyear}^{-1}\right)$. All stations show positive rates of visibility change in winter season except for Tiree $\left(-0.186 \pm 0.012 \mathrm{kmyear}^{-1}\right)$. It is also observed that Alder- 
grove station shows a negative rate of visibility change in the summer season $\left(-0.417 \pm 0.036 \mathrm{~km}\right.$ year $\left.^{-1}\right)$.

The improvement in median visibility at most of the sites can be seen in Fig. S1 in the Supplement. Moreover, box plots of the decadal visibility are also produced showing the median, interquartile range, outliers etc. (see Fig. S2).

Improved visibility at most of the sites is due to reduction in air pollution and the likely changes in fuel use and consumption that took place after 1956 Clean Air Act. The Clean Air Act was introduced with the aims of reducing smog, smoke and sulfur dioxide concentrations in the environment. In particular, the policy focused on industrial emission sources and reduction (Williams, 2004). Recently, Harrison et al. (2015) shown that concentration of sulfur dioxide, coal smoke, nitrogen dioxide, suspended matter (black smoke) and PM were significantly reduced in the UK over the last 5 decades as the result of switching to cleaner fuels after the 1956 Clean Air Act.

Rainfall data have been used to investigate the impact on visibility for all eight study stations. Daily rainfall data from 12:00 averaged over each year are shown in Fig. S3. Figure $\mathrm{S} 4$ shows a comparison between annual average visibility that has been filtered for when rainfall is present (hourly rainfall $>0 \mathrm{~mm}$ ) and non-filtered data. The percentage of data removed by filtering for rain accounts for $8-13 \%$ of the total data, dependent upon the site location, with the Tiree and Aldergrove sites having the highest percentage of rainfall. It is observed that filtering for rainfall only results in very small visibility increases for some stations. Overall the effect is negligible in most circumstances. Therefore the non-filtered data are used in this study.

\subsection{Evaluation of historical wind data}

\subsubsection{Wind roses for the eight stations}

A graphical representation of historical wind speed and direction at the eight chosen stations is shown in Fig. 1 using the wind rose polar co-ordinate representation. These graphs describe the most probable wind speeds and directions over the whole time series (Carslaw and Ropkins, 2012). As expected, the graphs show that the predominant wind directions in the UK are from the southwest. However, there are clear variations between the different stations. The range of wind speed varies from 0 to $35 \mathrm{~m} \mathrm{~s}^{-1}$ dependent upon location, with the more coastal sites experiencing greater average wind speeds.

\subsubsection{Analysis of influence of wind speed and wind direction on visibility}

Decadal-seasonal bivariate polar plots are presented for all eight stations in Fig. S7; these diagrams provide information on the variation of visibility with wind speed and direction and can suggest locations for visibility-degrading sources. The detailed analyses of each site are given below:

Aldergrove: overall, lower values of visibility were observed when the wind was from the south to east, while above-average values were collected when the wind was from the north to west. Intermediate visibility was generally observed when the wind came from the south to west or north to east quadrants. Distinct differences are observed between the different seasons. In particular, in the summer visibility with wind from the north to west was higher than in other seasons in every decade. It is clearly seen that visibility has improved the most when wind comes from the south to east, which covers mainland urban areas such as Belfast, the major regional city. It is noted that the seasonal and polar trends are similar between the visiometer (1950s-1990s) and human-derived (2000s-2010s) data sets even though the absolute magnitudes are different as noted above.

Heathrow: low visibility was observed whenever wind speeds were lower than $5 \mathrm{~m} \mathrm{~s}^{-1}$ in any direction, which implies a significant local source of visibility-degrading pollutants. Since Heathrow is the site of a major international airport, with commensurate road and other transport infrastructure, this is not surprising. Overall, lower visibility is also seen when the wind direction comes from the northeast to southeast, which is consistent with visibility-reducing pollution arriving from the greater London area. The highest visibilities are typically observed when the wind direction is from the north to southwest, which is consistent with the less densely populated surrounding areas. In particular during summer visibility in the northwest wind direction was higher than other seasons in every decade. It is identified that visibility has improved in all wind directions, but most significantly in the easterly direction, which covers the London urban centre. The change in visibility illustrates the dramatic improvement of air quality in London since the introduction of the Clean Air Act in the 1950s (Brimblecombe, 2006).

Leuchars: two distinct spatial groupings of visibility are clearly observed. When the wind direction comes from the northeast to southwest (clockwise), visibility is generally lower, and it is generally higher when the wind direction is from the northeast to southwest (anticlockwise). The lowest visibilities are from the southeast in all seasons. The spatial pattern of low visibility suggests a maritime aerosol source as the major source of visibility reduction, whilst high visibility was associated with air which had passed over predominantly rural Scotland. Visibility in the northwesterly wind direction was higher in the summer months, as expected (see Figs. 2 and 3), than in other seasons in every decade.

Nottingham: like Heathrow, the poorest visibility conditions occurred when wind speed was below $10 \mathrm{~m} \mathrm{~s}^{-1}$, suggesting local sources of visibility-degrading pollutants. Visibility is often lowest when the wind comes from the southeast, consistent with the relative placement of Nottingham city centre to this direction (the meteorological station is actually located in Watnall just about 5 miles from Notting- 
Table 2. Rate of change of visibility (in $\mathrm{km} \mathrm{year}^{-1}$ ) with their standard error at the $95 \%$ confidence interval.

\begin{tabular}{lrrrrrr}
\hline Satiation & Year & Annual & Winter & Spring & Summer & Autumn \\
\hline Plymouth & $1950-2012$ & $0.040 \pm 0.021$ & $0.152 \pm 0.017$ & $0.006 \pm 0.025$ & $-0.043 \pm 0.031$ & $0.049 \pm 0.022$ \\
Aldergrove & $1950-2002$ & $0.056 \pm 0.021$ & $0.110 \pm 0.019$ & $0.831 \pm 0.030$ & $-0.417 \pm 0.036$ & $0.074 \pm 0.029$ \\
Heathrow & $1950-2011$ & $0.201 \pm 0.018$ & $0.231 \pm 0.021$ & $0.181 \pm 0.020$ & $0.145 \pm 0.028$ & $0.226 \pm 0.020$ \\
Ringway & $1950-2004$ & $0.339 \pm 0.016$ & $0.331 \pm 0.020$ & $0.363 \pm 0.018$ & $0.316 \pm 0.025$ & $0.343 \pm 0.018$ \\
Waddington & $1950-2012$ & $0.293 \pm 0.010$ & $0.331 \pm 0.019$ & $0.245 \pm 0.016$ & $0.270 \pm 0.018$ & $0.325 \pm 0.016$ \\
Leuchars & $1957-2012$ & $0.157 \pm 0.019$ & $0.286 \pm 0.027$ & $0.140 \pm 0.030$ & $0.030 \pm 0.034$ & $0.180 \pm 0.025$ \\
Tiree & $1957-2002$ & $-0.089 \pm 0.014$ & $-0.186 \pm 0.014$ & $-0.035 \pm 0.015$ & $-0.098 \pm 0.015$ & $-0.046 \pm 0.015$ \\
Nottingham & $1957-2012$ & $0.235 \pm 0.023$ & $0.293 \pm 0.022$ & $0.214 \pm 0.024$ & $0.149 \pm 0.033$ & $0.270 \pm 0.022$ \\
\hline
\end{tabular}

ham city centre). Visibility is generally highest when the wind comes from the west and southwest directions, which is largely consistent with air masses passing over less urban areas compared to the other wind directions. During the summer months, visibility in the southwest was higher than in other seasons in every decade. It is clear from Fig. 2 that visibility has increased in all seasons, and the strongest improvement is seen in air from the southeast as seen in Fig. S7.

Plymouth: in general, the lowest visibility was observed when the wind comes from the southeast to southwest, which is consistent with maritime air causing the lowest visibility, which suggests a maritime source of aerosol causing visibility degradation. The highest visibilities are observed when wind comes from the northwest to northeast, and in particular the northeast; this is consistent with air masses passing over relatively rural areas. Regardless of the direction of wind, the summer months showed higher visibility than all other seasons. It is identified that visibility has improved over time for all wind directions.

Ringway: overall visibility was poor at low wind speeds and when the wind direction was from the northeast to southeast. Ringway is the location of Manchester International Airport, so, like Heathrow, there is likely to be a significant local source of visibility-degrading pollutants arising from the airport and its associated infrastructure. The wind directions associated with higher visibility are a lot more variable in time and space than other locations. However, in general, high wind speeds from either the northwest or southwest directions are often associated with higher visibility. Since the 1960 s visibility has improved for all wind directions. In particular, visibility associated with air masses coming from the direction of the greater Manchester area to the north has shown a marked increase since the 1970 s.

Tiree: the island of Tiree has by far the highest visibility at low wind speeds. Overall low visibility was observed when wind came from the west to southeast, while highest visibility occurred with wind from the northeast. The spatial variation of low visibility is consistent with a maritime source of visibility-impairing aerosols. The higher the wind speed, typically the lower the visibility, which is consistent with greater aerosol production from greater wave activity (Venkataraman et al., 2002). The higher visibility from the northeast is consistent with air masses passing over the larger rural highlands of Scotland. Visibility was relatively stable for all wind directions for all decades of the human observation data series, which is consistent with this rural maritime site being largely unperturbed by anthropogenic pollution.

Waddington: in general, lower visibility is observed when wind speeds are lower than $10 \mathrm{~ms}^{-1}$, which is consistent with local pollution sources. Low visibility is also observed when the wind direction is from the east to southeast, which potentially indicates a maritime source. Higher visibility is observed from the west at high wind speeds. Visibility has improved for wind from all directions since the 1970s.

Overall it is clear that visibility has improved at most of the sites for most local wind directions. The most marked improvements in visibility are seen in directions in which air masses pass over major metropolitan areas such as greater London and greater Manchester. Whilst most of the visibility changes can be ascribed to the location of the meteorological stations with respect to either urban or maritime sources, it is noted that for most sites the wind direction with the lowest visibility overall is often from the east, i.e. continental Europe, and hence synoptic-scale pollution events which affect visibility. Poor air quality, in the UK, is often associated with synoptic-scale events originating in continental Europe (Charron et al., 2007a, b, 2013; Lee et al., 2006; Crilley et al., 2015)

\subsection{Correlation between $\mathrm{RH}$ and visibility: seasonal, day-of-the-week and decadal effects}

Figure 3 provides monthly values for visibility and $\mathrm{RH}$, averaged over the whole time series, for each station. This figure clearly illustrates that visibility shows a strong seasonal cycle which is anti-correlated with RH at all stations. The relationship at Tiree is less strong compared to the other seven sites. The geographical location of Tiree, which is a maritime island, is the likely reason for the $\mathrm{RH}$ trend being different to the other stations. Tiree island has a very flat landscape, which does not provide shelter from wind in any direction; this directly affects the local meteorology (Holliday, 2004). Overall, the monthly trends indicate that visibility is lowest 

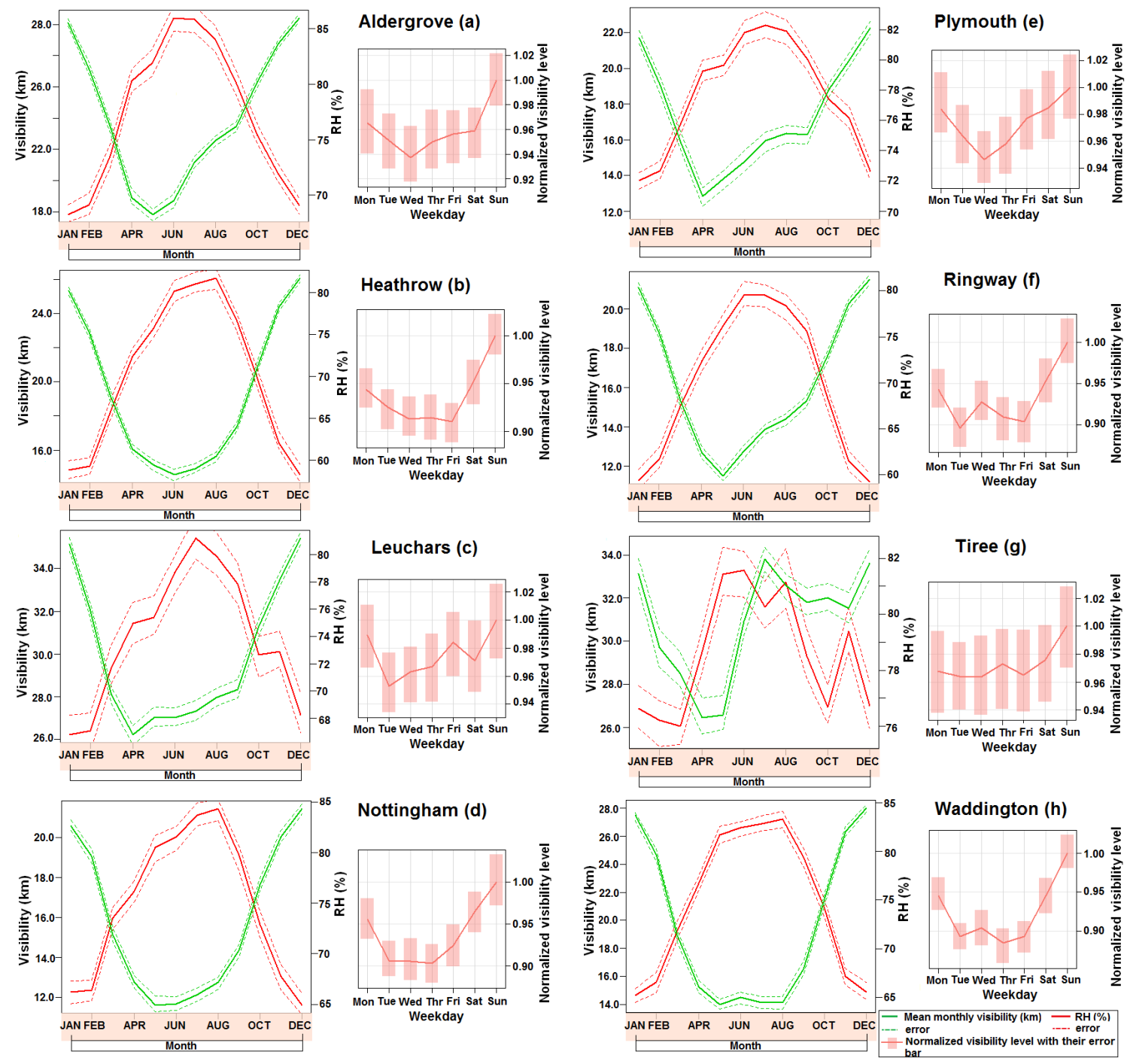

Figure 3. Mean monthly visibility and RH (left side) and average weekday visibility normalized to Sunday mean values (right side) at all eight sites: (a) Aldergrove, (b) Heathrow, (c) Leuchars, (d) Nottingham, (e) Plymouth, (f) Ringway, (g) Tiree, (h) Waddington.

in winter and highest in summer, with spring and autumn being intermediate in visibility values.

In addition to the seasonal cycle, there is a clear day-ofthe-week effect on visibility changes at most sites (Fig. 3), where visibility improves sharply at the weekend, with Sunday showing the highest visibility. It is observed that visibility improves on Sunday from 5 to $12.5 \%$ (depending upon area) as compared to other weekdays (Monday-Friday). Lower traffic and industrial emissions at the weekend are the likely reasons for better visibility at the weekend due to less pollutant emissions. The inherent assumption in this analysis is that traffic is higher during weekdays than during the weekend. It is noted that visibility tends to peak on Sunday (rather than both Saturday and Sunday), and this may reflect the non-negligible timescale required for pollutant removal by wind-driven dispersion; i.e. the build-up of pollution dur- ing weekdays is not fully dispersed until Sunday. The same argument explains why visibility is typically higher on Mondays than the other weekdays later in the week.

The long-term decadal (1950s-2010s) variation in visibility with RH is shown in Fig. 4, for all eight stations, where the visibility is averaged within RH bins. A qualitatively similar pattern has been observed for all stations: visibility is observed to vary strongly with relative humidity, which clearly indicates a significant particle hygroscopicity effect on visibility. It is noted that very high RH can also be indicative of precipitation, which also decreases visibility.

To further highlight the effect of RH on visibility, the mean monthly visibility trend is compared to RH for the 60 years of data recorded at the Waddington station; see Fig. S5. A scatter plot of visibility versus RH reveals a clear nearlinear relationship (linear fit $R^{2}=0.60$ ) between the vari- 

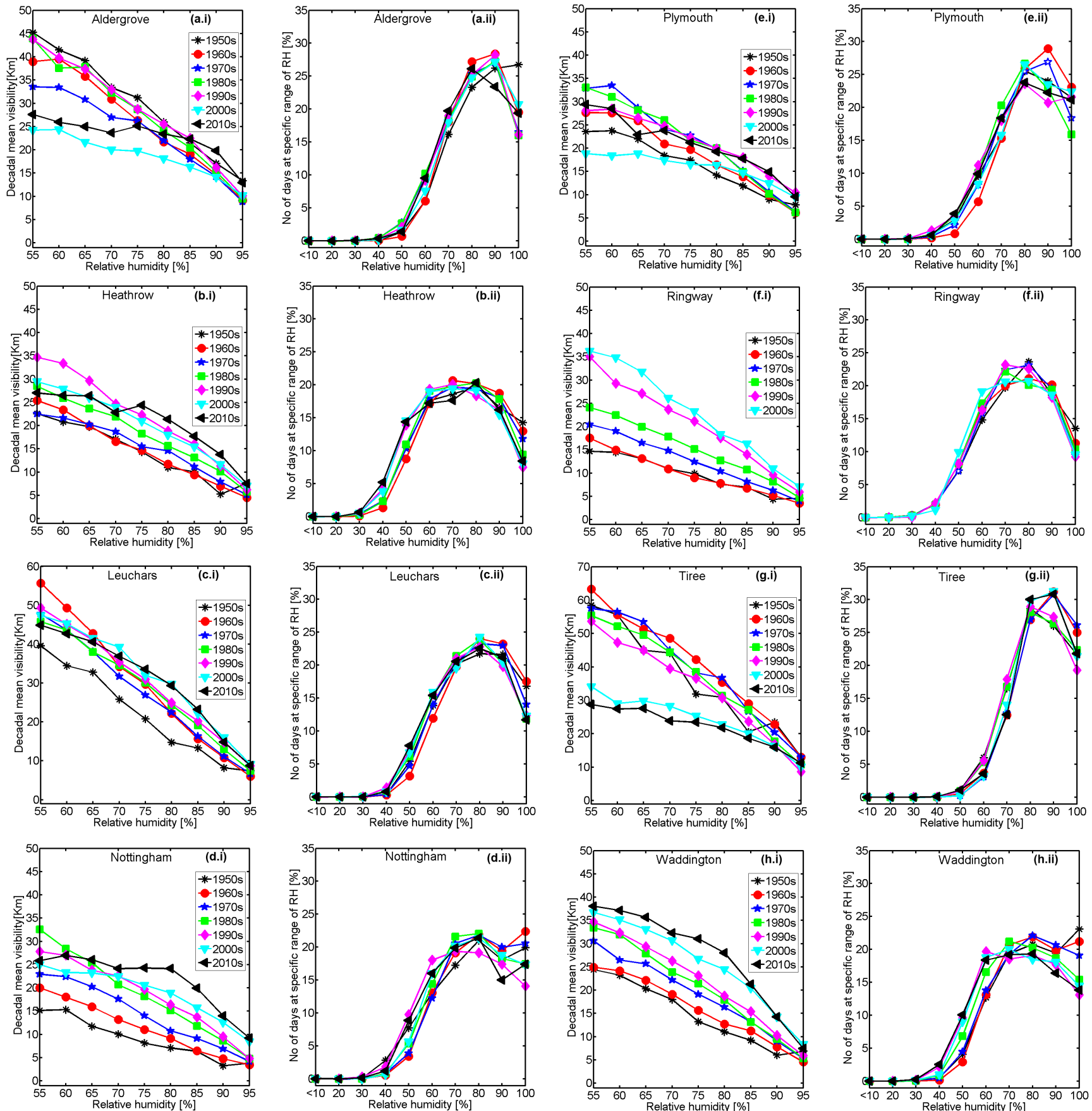

Figure 4. Decadal visibility in a specific range of relative humidity (left side) and number of days in percent during different relative humidity (right side).

ables. Removal of the long-term trend in the visibility data was achieved by fitting the visibility to a quadratic function and subtracting the quadratic function from the time series. A scatter plot of the long-term detrended visibility data versus $\mathrm{RH}$ reveals a more linear relationship $\left(R^{2}=0.66\right)$ where every rise in $\mathrm{RH}$ of $10 \%$ results in a reduction of approximately $5 \mathrm{~km}$ of visibility.

\subsection{Effect of long-term changes in meteorological parameters upon visibility}

The long-term trends in visibility are compared to the other recorded meteorological parameters: $\mathrm{RH}$, air temperature, wind speed and wind direction (Fig. S6). It is observed that at most of the stations RH decreases as average air tempera- 
ture increases. The previous literature has observed that the UK mean air temperature and sea surface temperature have increased by about 1 and $0.7^{\circ} \mathrm{C}$, respectively, between the early 1970s and mid-2000s (Jenkins, 2007). However, overall UK mean RH decreased about $2.7 \%$ between 1961 and 2006 (Jenkins, 2007). This reduction in RH is also seen more widely at the mid-latitudes (Willett et al., 2014). The temperature change is likely due to climate change, land-use (urban heat island) effects or a combination of both. Clearly, urban heat island effects can only affect stations that are located in urban areas (Fig. S6). However, as Fig. S6 shows, visibility is strongly related to relative humidity and hence to the air temperature of a given location, highlighting a possible indirect effect of climate change and urban heat island effects on regional visibility. The correlation statistics between visibility, relative humidity, air temperature and wind speed are provided for all stations in Table S2.

\subsection{Mathematical fitting of measured visibility}

Equations (5) and (6) were fit to the decadal visibility data subset into distinct RH bins, as detailed in Sect. 3.2. It is found that the fitted data are able to match the observed visibility extremely well $\left(R^{2}>0.98\right)$ for all stations; for example see Fig. 5 for Heathrow station. The last decade, starting in 2010, has the poorest fit, albeit still with an $R^{2}=0.95$, but only cosists of 3 years of data.

We have quantified, in Sect. 4.1, that the decadal observed visibility has improved at most of the stations, which is a direct indicator of change in the combination of aerosol concentration, aerosol composition, gas concentration and RH. To better understand these changes in visibility, the absorption coefficient $\left(\beta_{\text {abs }}\right)$, scattering coefficient $\left(\beta_{\text {sca }}\right)$, particle hygroscopicity parameter $(\gamma)$ and dry visibility (Vis(dry)) have all been calculated via the constructed model (Eq. 4) described in Sect. 3.2.

The determined model output parameters (Vis(dry), $\gamma$, $\beta_{\text {sca }}$ and $\beta_{\text {abs }}$ ) are presented in Fig. 6, where analysis has been carried out for all sites within each decade; however, the following discussion only considers data that were measured manually, due to the impacts of measurement methodology changes noted above. A clear improvement in calculated dry visibility was observed for Plymouth, Heathrow, Ringway, Nottingham and Waddington, while only minor changes were observed at Aldergrove, Leuchars and Tiree (Fig. 6a and Table S3). Broadly, the five sites in England are similar with all showing an upwards trend in visibility, whereas the Scottish and Northern Irish sites have greater dry visibilities but less of a discernible trend with time.

The derived value for $\gamma$ has decreased slightly at Heathrow, Leuchars and Ringway sites over those decades (Fig. 6b and Table S2), which indicates a decrease in hygroscopicity over the time (and a concomitant improvement in visibility). Tiree is the only station which showed increased hygroscopicity parameter values, implying a rise in aerosol
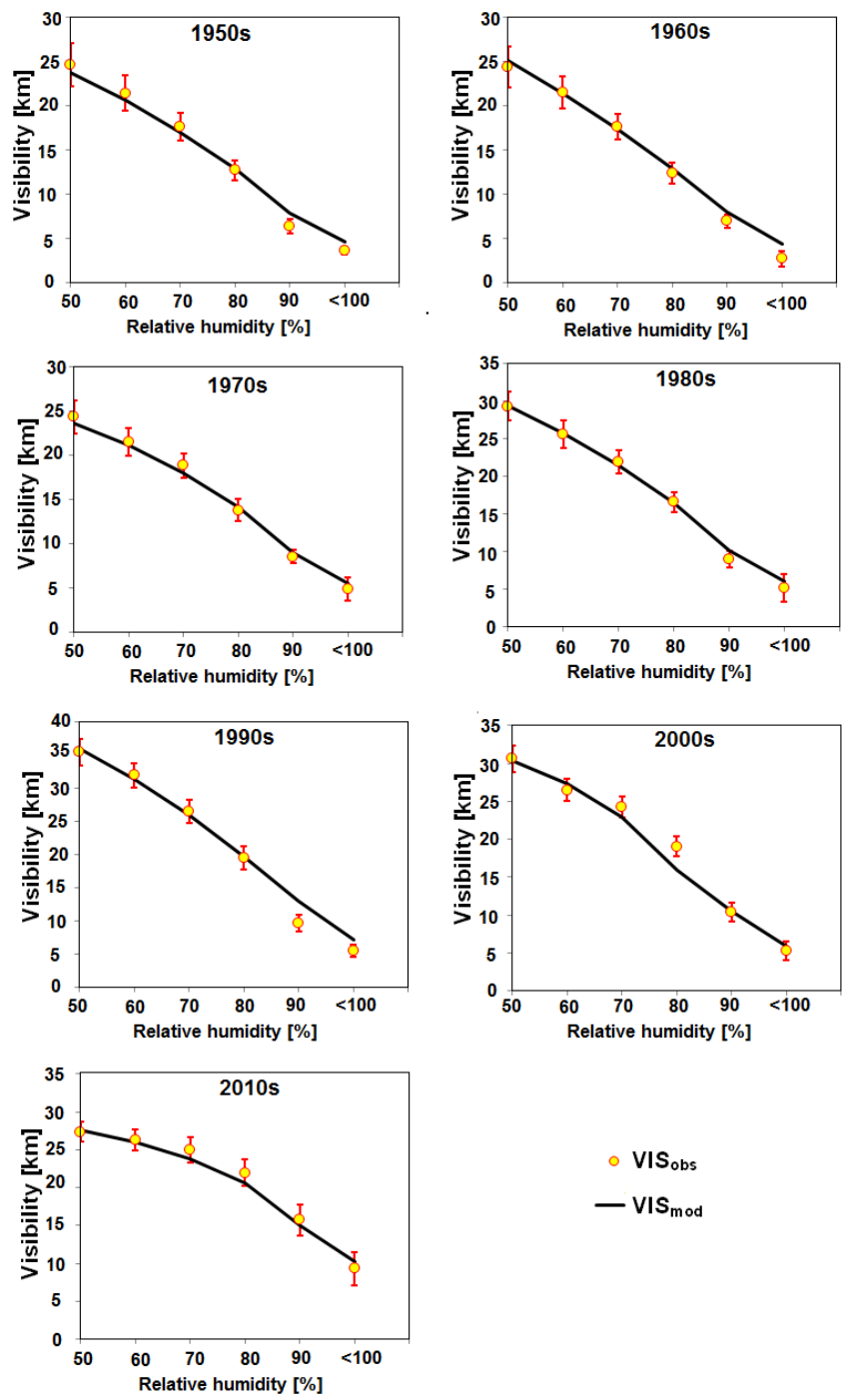

Figure 5. Comparisons of modelled and observed visibility in a specific range of RH using Eq. (4) at Heathrow station. The observed visibility is presented with standard error bars at the $95 \%$ confidence interval.

particle hygroscopicity, which results in a drop in visibility. The other stations like Aldergrove, Ringway, Plymouth and Waddington show very little change in hygroscopicity parameter values.

Reductions in scattering coefficient are observed at all sites except Aldergrove. The scattering coefficients calculated at $\mathrm{RH}=75 \%$ are shown in Fig. 6d. Larger decreases in the scattering coefficient are observed at the urban sites than at the rural sites. Reductions are also observed in the absorption coefficient at most sites, but there is much more variability than in the scattering coefficient. It is interesting to note that the two most remote sites, both in Scotland, have increasing absorption coefficients, which is potentially indicative of episodes of long-range transport of absorbing aerosol 

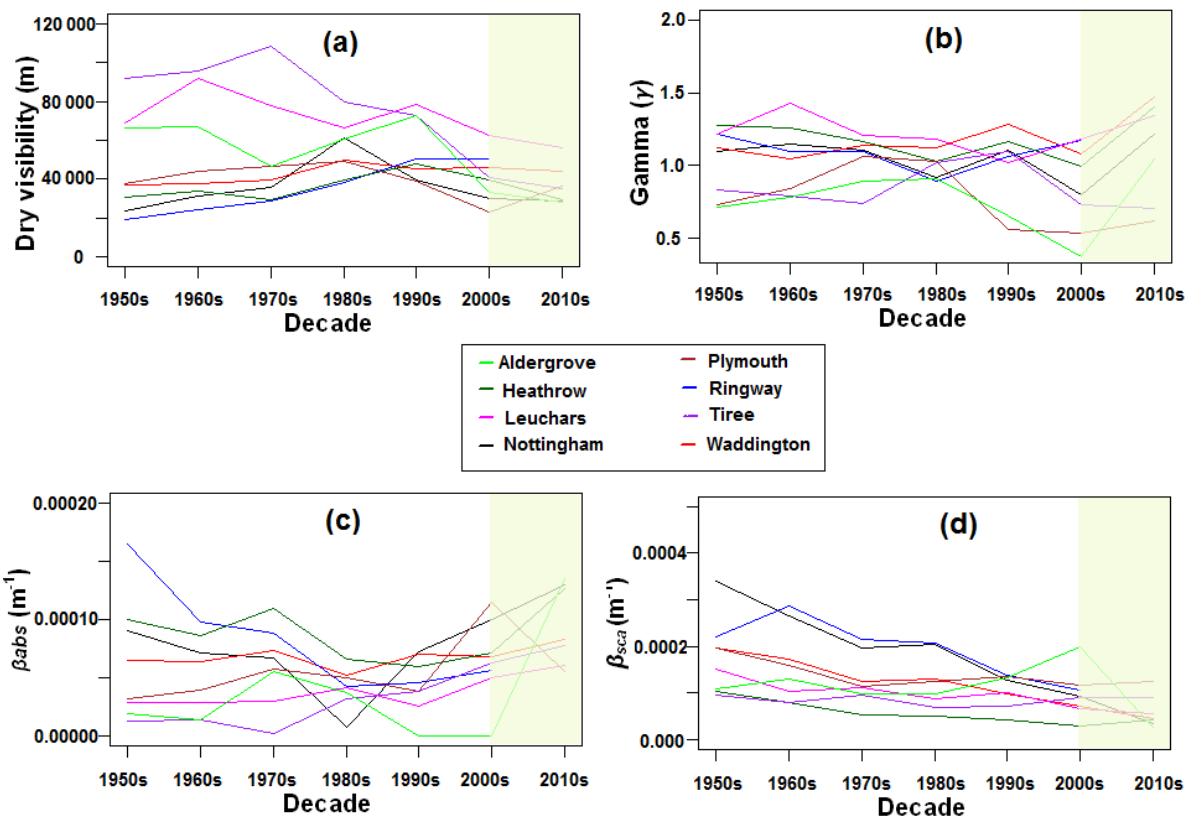

$$
\begin{aligned}
& \text { - Plymouth } \\
& \text { - Ringway } \\
& \text { - Tiree } \\
& \text { - Waddington }
\end{aligned}
$$

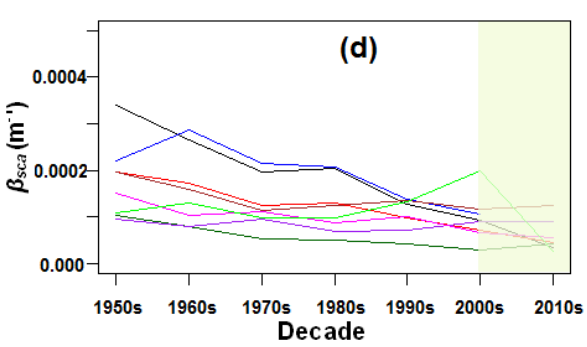

Figure 6. Model output parameters (a) dry visibility and (b) gamma, and (c) absorption coefficient and (d) scattering coefficient at $75 \%$ from the 1950s to 2010s. The green shaded region shows the start of the visiometer era at most of the stations (see Table S1 to see the starting year of visiometer measurement).

to these pristine sites becoming more frequent. As expected, both the absorption and scattering coefficients show an inverse relationship with the observed visibility (Fig. 6a, c).

The change in the fitted values for dry visibility and the scattering coefficient is not significantly affected by the change in visibility measurement from human observation to visiometers. Contrastingly, the absorption coefficient and gamma values are much more influenced by measurement technique. This likely indicates that local sources have markedly different absorption and hygroscopicity parameters compared to more regional sources, whereas their local and regional scattering properties are relatively similar.

The modelled scattering coefficient, at $75 \% \mathrm{RH}$, is always higher than the absorption coefficient for all sites and times. However, at lower RH the two values become more comparable; see Fig. S8, which examines the contribution of the scattering coefficient to the total extinction coefficient at Heathrow. The non-negligible contribution of the absorption coefficient to the total extinction coefficient indicates that the model shown in Eq. (5) is not appropriate for the data reported in this paper. However, for other locations with lower concentrations of absorbing species, gas or aerosol, the model may be valid, and the benefit of a linear fitting algorithm, compared to a non-linear algorithm, could be exploited. It is shown the contribution of aerosol scattering to total extinction has remained relatively constant over time, which indicates that the reduction in particulate matter has decreased both the absorbing and scattering fractions in equal measure.
Seasonal decadal changes in aerosol parameters were calculated for the Heathrow station (Fig. S9). In general, an improved dry visibility with reduced $\beta_{\text {abs }}$ and $\gamma$ values was observed for all seasons over time. However, during winter months the greatest improvement in dry visibility with a reduction in $\beta_{\text {abs }}$ was noted.

Trends in visibility for those data acquired at a single $\mathrm{RH}$ value of $70 \%(67.5-72.5 \%)$ during the period of the 1950 s to 1990s were investigated for the Heathrow site to demonstrate the disaggregation of the RH effect on visibility from the aerosol concentration effect upon visibility. At constant $\mathrm{RH}$, a clearly improved visibility was determined for the study period (Fig. S10). The result implies that significant changes in aerosol composition/concentration are driving the visibility trend. Hence improving air quality contributes significantly to better visibility.

\subsection{Effect of nitrogen dioxide gas upon visibility at Heathrow}

The potential influence of $\mathrm{NO}_{2}$ levels upon visibility was analysed using data from the Harlington station (proximate to the Heathrow site) for the period 2004-2012. The annual mean concentration of $\mathrm{NO}_{2}$ varied from 33.6 to $38.5 \mu \mathrm{g} \mathrm{m}{ }^{-3}$, peaking in 2005 (Table 3). The $\mathrm{NO}_{2}$ influence on observed visibility (in the RH bin centred at $75 \%(72.5-77.5 \%)$ ) was greatest in the year of 2005 (where it contributed $4.7 \pm 1.6 \%$ in total extinction) and lowest for $2012(3.3 \pm 1.5 \%$ in total extinction), with the remaining visibility reduction being caused by aerosol extinction. Overall, during 2004-2012 
Table 3. Gas contribution to visibility change over Heathrow airport.

\begin{tabular}{lrrrrr}
\hline Year & $\begin{array}{r}\mathrm{NO}_{2} \\
\text { concentration } \\
\left(\mu \mathrm{g} \mathrm{m}^{-3}\right)\end{array}$ & $\begin{array}{r}\mathrm{NO}_{2} \\
(\mathrm{ppm})\end{array}$ & $\begin{array}{r}\text { Total extinction } \\
\text { coefficient }\left(\mathrm{km}^{-1}\right) \\
\text { by all effects } \\
\text { (using E1) }\end{array}$ & $\begin{array}{r}\text { Absorption } \\
\text { coefficient in km } \\
\left(\beta_{\mathrm{NO}_{2} \text { abs }}\right) \\
\text { by NO}\end{array}$ & $\begin{array}{r}\text { \% contribution of } \mathrm{NO}_{2} \\
\text { in total } \\
\text { extinction } \\
\text { coefficient }\end{array}$ \\
\hline 2004 & 38.3 & 0.0203 & 0.1475 & $0.00671 \pm 0.0023$ & $4.5 \pm 1.5$ \\
2005 & 38.5 & 0.0204 & 0.1425 & $0.00675 \pm 0.0023$ & $4.7 \pm 1.6$ \\
2006 & 36.9 & 0.0196 & 0.1978 & $0.00648 \pm 0.0022$ & $3.3 \pm 1.1$ \\
2007 & 36.9 & 0.0197 & 0.1855 & $0.00649 \pm 0.0029$ & $3.5 \pm 1.4$ \\
2008 & 34.7 & 0.0185 & 0.1759 & $0.00600 \pm 0.0026$ & $3.4 \pm 1.4$ \\
2009 & 36.3 & 0.0193 & 0.1681 & $0.00636 \pm 0.0023$ & $3.8 \pm 1.2$ \\
2010 & 34.4 & 0.0183 & 0.1755 & $0.00604 \pm 0.0023$ & $3.4 \pm 1.3$ \\
2011 & 33.6 & 0.0179 & 0.1614 & $0.00589 \pm 0.0025$ & $3.6 \pm 1.5$ \\
2012 & 34.6 & 0.0184 & 0.1550 & $0.00507 \pm 0.0024$ & $3.5 \pm 1.5$ \\
$1970^{*}$ & 69.2 & 0.0368 & 0.2370 & 0.0121 & 5.12 \\
\hline
\end{tabular}

* Estimated values given for 1970 (see main text for details).

$\mathrm{NO}_{2}$ contributed approximately $4 \%$ to the observed visibility change, while the remaining $96 \%$ contributed arose from aerosol particles and fog. However it is worth considering the contribution of $\mathrm{NO}_{2}$ towards the total extinction coefficient during the $1970 \mathrm{~s}$, when visibility was very low $(16.5 \mathrm{~km})$ as compared to $2012(25.2 \mathrm{~km})$ and $\mathrm{NO}_{2}$ levels being higher. Unfortunately $\mathrm{NO}_{2}$ data are not available before 2004 at the nearby Heathrow site, but a recent study shows that $\mathrm{NO}_{x}$ emission in the UK has almost doubled in the time period 1970-2012 (Harrison et al., 2015). Using the UK NO${ }_{x}$ record for 1970 from Harrison et al. (2015), we assumed the annual mean $\mathrm{NO}_{2}$ concentration in 1970 is double what is measured in the year $2012\left(34.6 \mu \mathrm{g} \mathrm{m}^{-3}\right)$ as emission estimates are approximately related to concentration. This assumption does not take into account the changing vehicle fleet with corresponding changing emissions of $\mathrm{NO}$ and $\mathrm{NO}_{2}$ (Carslaw and Rhys-Tyler, 2013). Using these data the absorption coefficient for $\mathrm{NO}_{2}$ was calculated. In particular, a higher absorption coefficient $\left(\beta_{\mathrm{NO}_{2} \text { abs }}\right)$ in $1970\left(0.0121 \mathrm{~km}^{-1}\right)$ than in 2012 $\left(0.00507 \mathrm{~km}^{-1}\right)$ was identified. However, the contribution of $\mathrm{NO}_{2}$ to the total extinction coefficient remained at $5.2 \%$ in 1970, only about $2 \%$ higher than in 2012.

\section{Conclusions}

Long-term trends in visibility for eight meteorological stations situated in the UK have been investigated. In general, visibility has improved at most of the stations through time. The improvements are greatest in urban areas and are attributed to reductions in aerosol particle loadings and decreases in atmospheric RH. Visibility was found to be lowest during winter and highest in the summer due to seasonal variations in RH and likely changes in the mixing-layer height. The rate of change of visibility was higher in winter for all stations with the exception of Ringway. A sharp positive in- crement (5-12.5\%) in visibility was observed on Sundays, as compared to other days of the week (Monday-Saturday), which is most likely due to weekend reductions in traffic and other particulate matter emission sources.

Bivariate polar plots of visibility, which account for both the influence of both wind speed and wind direction, explained the influence of wind on likely source areas of visibility-reducing aerosols. These bivariate polar plots identified likely locations for visibility-reducing pollutant sources and their variation over time. Overall, an improved visibility at most of the stations in almost all directions was observed with notable improvements when the air masses moved over metropolitan areas, for example, greater Manchester and greater London areas. At most sites, low visibility was observed when the winds came from the direction of continental Europe, which may indicate an influence of regional pollution events leading to visibility reductions. Significant changes in visibility were observed with changes in relative humidity, which indicates a strong dependency of visibility on aerosol hygroscopicity. The measured RH at all sites was typically in the range of 60-80\%, and variations of a few percent in this RH range can have significant effects on visibility. Many sites showed long-term decreases in RH, which correlated with increases in air temperature, and had the effect of improving visibility. If the trend of increasing RH continues, the UK can expect further improvements in visibility for the same pollutant loading.

Calculations indicate that the majority of visibility reduction is caused by PM; however, a non-negligible contribution of light absorption is due to $\mathrm{NO}_{2}$ gas. For the Heathrow station, over the time period 2004-2012, light absorption by $\mathrm{NO}_{2}$ was calculated to contribute approximately $4 \%$ to the total visibility reduction, with the remainder caused by PM absorption and scattering. The $\mathrm{NO}_{2}$ contribution was likely to have been significantly higher in prior decades due to 
the higher $\mathrm{NO}_{x}$ emissions and hence atmospheric concentrations.

A light-extinction model was developed to explain the dependency of visibility upon meteorology and aerosol characteristics. The agreement between the modelled and measured visibility is excellent. The model suggests that there have been significant changes in aerosol concentration over the last 60 years. The model incorporates parameterizations of aerosol hygroscopicity, particle concentration, particle scattering, and particle and gas absorption. The developed model is easily transferrable and applicable to other data sets worldwide.

Visibility can be used as a proxy for aspects of air quality, in particular particulate matter and nitrogen dioxide. Visibility measurements can extend back for hundreds of years, whilst air quality measurements typically only go back decades, albeit with a few sparse data sets going back longer in time. The approach demonstrated in this paper has potential for generating historical air quality indications for locations with visibility records.

\section{Data availability}

Hourly visibility data along with meteorological parameters can be downloaded at http://badc.nerc.ac.uk/. $\mathrm{NO}_{2}$ data used in this study are available at https://uk-air.defra.gov.uk/.

\section{The Supplement related to this article is available online at doi:10.5194/acp-17-2085-2017-supplement.}

Competing interests. The authors declare that they have no conflict of interest.

Acknowledgements. We thank the University of Birmingham for supporting Ajit Singh through the Elite Scholarship Scheme. We are also thankful to the UK Met Office and Defra for the provision of data used in this research. We also appreciate both reviewers for their valuable comments and suggestions, which have improved the quality of the manuscript.

Edited by: T. Takemura

Reviewed by: two anonymous referees

\section{References}

Appel, B., Tokiwa, Y., Hsu, J., Kothny, E., and Hahn, E.: Visibility as related to atmospheric aerosol constituents, Atmos. Environ., 19, 1525-1534, 1985.

Brimblecombe, P.: The big smoke, Methuen London, New York, 1987.
Brimblecombe, P.: The clean air act after 50 years, Weather, 61, 311-314, 2006.

Cao, J.-j., Wang, Q.-y., Chow, J. C., Watson, J. G., Tie, X.-x., Shen, Z.-x., Wang, P., and An, Z.-s.: Impacts of aerosol compositions on visibility impairment in Xi' an, China, Atmos. Environ., 59, 559-566, 2012.

Carslaw, D. C. and Rhys-Tyler, G.: New insights from comprehensive on-road measurements of $\mathrm{NO}_{x}, \mathrm{NO}_{2}$ and $\mathrm{NH}_{3}$ from vehicle emission remote sensing in London, UK, Atmos. Environ., 81, 339-347, 2013.

Carslaw, D. C. and Ropkins, K.: Openair - an R package for air quality data analysis, Environ. Modell. Softw., 27, 52-61, 2012.

Chang, D., Song, Y., and Liu, B.: Visibility trends in six megacities in China 1973-2007, Atmos. Res., 94, 161-167, 2009.

Charron, A., Birmili, W., and Harrison, R. M.: Factors influencing new particle formation at the rural site, Harwell, United Kingdom, J. Geophys. Res., 112, D14210, doi:10.1029/2007JD008425, 2007a.

Charron, A., Harrison, R. M., and Quincey, P.: What are the sources and conditions responsible for exceedences of the $24 \mathrm{~h} \mathrm{PM}_{10}$ limit value $\left(50 \mathrm{\mu g} \mathrm{m}^{-3}\right)$ at a heavily trafficked London site?, Atmos. Environ., 41, 1960-1975, 2007b.

Charron, A., Degrendele, C., Laongsri, B., and Harrison, R. M.: Receptor modelling of secondary and carbonaceous particulate matter at a southern UK site, Atmos. Chem. Phys., 13, 1879-1894, doi:10.5194/acp-13-1879-2013, 2013.

Clarke, A., Gascoigne, M., Henderson-Sellers, A., and Williams, A.: Modelling air pollution in Leeds (UK), Int. J. Environ. Stud., 12, 121-132, 1978.

Colbeck, I. and Harrison, R. M.: Ozone-secondary aerosolvisibility relationships in North-West England, Sci. Total Environ., 34, 87-100, doi:10.1016/0048-9697(84)90043-3, 1984.

Colvile, R., Hutchinson, E., Mindell, J., and Warren, R.: The transport sector as a source of air pollution, Atmos. Environ., 35, 1537-1565, 2001.

Crilley, L. R., Bloss, W. J., Yin, J., Beddows, D. C. S., Harrison, R. M., Allan, J. D., Young, D. E., Flynn, M., Williams, P., Zotter, P., Prevot, A. S. H., Heal, M. R., Barlow, J. F., Halios, C. H., Lee, J. D., Szidat, S., and Mohr, C.: Sources and contributions of wood smoke during winter in London: assessing local and regional influences, Atmos. Chem. Phys., 15, 3149-3171, doi:10.5194/acp15-3149-2015, 2015.

Defra: Air Pollution in the UK 2010, A report prepared by AEA for Defra and the Devolved Administrations Department for Environment, Food and Rural Affairs, London, 2011.

Diederen, H., Guicherit, R., and HolLonder, J.: Visibility reduction by air pollution in the Netherlands, Atmos. Environ., 19, 377383, 1985 .

Doyle, M. and Dorling, S.: Visibility trends in the UK 1950-1997, Atmos. Environ., 36, 3161-3172, 2002.

Ferman, M. A., Wolff, G. T., and Kelly, N. A.: An assessment of the gaseous pollutants and meteorological conditions associated with Denver's brown cloud, J. Environ. Sci. Heal. A, 16, 315339, 1981.

Founda, D., Kazadzis, S., Mihalopoulos, N., Gerasopoulos, E., Lianou, M., and Raptis, P. I.: Long-term visibility variation in Athens (1931-2013): a proxy for local and regional atmospheric aerosol loads, Atmos. Chem. Phys., 16, 11219-11236, doi:10.5194/acp-16-11219-2016, 2016. 
Gomez, B. and Smith, C.: Atmospheric pollution and fog frequency in Oxford, 1926-1980, Weather, 39, 379-384, 1984.

Gomez, B. and Smith, C.: Visibility at Oxford, 1926-1985, Weather, 42, 98-106, 1987.

Groblicki, P. J., Wolff, G. T., and Countess, R. J.: Visibility-reducing species in the Denver "brown cloud" - I. Relationships between extinction and chemical composition, Atmos. Environ., 15, 2473-2484, 1981.

Hänel, G.: Computation of the extinction of visible radiation by atmospheric aerosol particles as a function of the relative humidity, based upon measured properties, J. Aerosol Sci., 3, 377-386, 1972.

Harris, B. and Smith, K.: Cleaner air improves visibility in Glasgow, Geography, 67, 137-139, 1982.

Harrison, R. M., Jones, A. M., and Lawrence, R. G.: Major component composition of $\mathrm{PM}_{10}$ and $\mathrm{PM}_{2.5}$ from roadside and urban background sites, Atmos. Environ., 38, 4531-4538, 2004.

Harrison, R. M., Pope, F. D., and Shi, Z.: Trends in Local Air Quality 1970-2014, in: Still Only One Earth: Progress in the 40 Years Since the First UN Conference on the Environment, The Royal Society of Chemistry, 58-106, 2015.

Haywood, J. and Boucher, O.: Estimates of the direct and indirect radiative forcing due to tropospheric aerosols: A review, Rev. Geophys., 38, 513-543, 2000.

Holliday, J.: Winds of Change "An exhibition about the history of Tiree's weather station and early flights to the island", An Iodhlann Scarinish, Isle of Tiree, 2004.

Husar, R. B., Holloway, J. M., Patterson, D. E., and Wilson, W. E.: Spatial and temporal pattern of eastern US haziness: a summary, Atmos. Environ., 15, 1919-1928, 1981.

Jayamurugan, R., Kumaravel, B., Palanivelraja, S., and Chockalingam, M.: Influence of temperature, relative humidity and seasonal variability on ambient air quality in a coastal urban area, International Journal of Atmospheric Sciences, 2013, 264046, doi:10.1155/2013/264046, 2013.

Jebson, S.: Fact sheet number 17: Weather observations, 2008.

Jenkins, G. J.: The climate of the United Kingdom and recent trends, Met Office Hadley Centre, Exeter, 2007.

Jinhuan, Q. and Liquan, Y.: Variation characteristics of atmospheric aerosol optical depths and visibility in North China during 1980 1994, Atmos. Environ., 34, 603-609, 2000.

Kong, S. F., Li, L., Li, X. X., Yin, Y., Chen, K., Liu, D. T., Yuan, L., Zhang, Y. J., Shan, Y. P., and Ji, Y. Q.: The impacts of firework burning at the Chinese Spring Festival on air quality: insights of tracers, source evolution and aging processes, Atmos. Chem. Phys., 15, 2167-2184, doi:10.5194/acp-15-2167-2015, 2015.

Koschmieder, H.: Theorie der horizontalen Sichtweite, Beiträge zur Physik der freien Atmosphäre, Meteorol. Z., 12, 33-55, 1924.

Lack, D. A. and Cappa, C. D.: Impact of brown and clear carbon on light absorption enhancement, single scatter albedo and absorption wavelength dependence of black carbon, Atmos. Chem. Phys., 10, 4207-4220, doi:10.5194/acp-10-4207-2010, 2010.

Lee, D.: Trends in summer visibility in London and southern England 1962-1979, Atmos. Environ., 17, 151-159, 1983.

Lee, D.: A preliminary analysis of long-term visibility trends in central scotland, J. Climatol., 5, 673-680, 1985.

Lee, D.: Regional Variations in Longterm Visibility Trends in the UK, 1962-1990, Geography, 108-121, 1994.
Lee, D. O.: The influence of wind direction, circulation type and air pollution emissions on summer visibility trends in southern England, Atmos. Environ. A-Gen., 24, 195-201, 1990.

Lee, J. D., Lewis, A. C., Monks, P. S., Jacob, M., Hamilton, J. F., Hopkins, J. R., Watson, N. M., Saxton, J. E., Ennis, C., and Carpenter, L. J.: Ozone photochemistry and elevated isoprene during the UK heatwave of August 2003, Atmos. Environ., 40, 75987613, 2006.

Liu, X., Zhang, Y., Cheng, Y., Hu, M., and Han, T.: Aerosol hygroscopicity and its impact on atmospheric visibility and radiative forcing in Guangzhou during the 2006 PRIDE-PRD campaign, Atmos. Environ., 60, 59-67, 2012.

Liu, Y. and Daum, P. H.: The effect of refractive index on size distributions and light scattering coefficients derived from optical particle counters, J. Aerosol Sci., 31, 945-957, 2000.

Malm, W. C., Walther, E. G., O’Dell, K., and Kleine, M.: Visibility in the southwestern United States from summer 1978 to spring 1979, Atmos. Environ., 15, 2031-2042, 1981.

Park, R. J., Jacob, D. J., Chin, M., and Martin, R. V.: Sources of carbonaceous aerosols over the United States and implications for natural visibility, J. Geophys. Res., 108, 4355, doi:10.1029/2002JD003190, 2003.

Park, R. J., Jacob, D. J., Kumar, N., and Yantosca, R. M.: Regional visibility statistics in the United States: Natural and transboundary pollution influences, and implications for the Regional Haze Rule, Atmos. Environ., 40, 5405-5423, 2006.

Sati, A. P. and Mohan, M.: Analysis of air pollution during a severe smog episode of November 2012 and the Diwali Festival over Delhi, India, Int. J. Remote Sens., 35, 6940-6954, 2014.

Schichtel, B. A., Husar, R. B., Falke, S. R., and Wilson, W. E.: Haze trends over the United States, 1980-1995, Atmos. Environ., 35, 5205-5210, 2001.

Seidel, D. J. and Birnbaum, A. N.: Effects of Independence Day fireworks on atmospheric concentrations of fine particulate matter in the United States, Atmos. Environ., 115, 192-198, 2015.

Singh, A. and Dey, S.: Influence of aerosol composition on visibility in megacity Delhi, Atmos. Environ., 62, 367-373, 2012.

Singh, A., Bloss, W. J., and Pope, F. D.: Remember, remember the 5th of November; gunpowder, particles and smog, Weather, 70, 320-324, 2015.

Sloane, C. S.: Summertime visibility declines: meteorological influences, Atmos. Environ., 17, 763-774, 1983.

Tang, I. N.: Chemical and size effects of hygroscopic aerosols on light scattering coefficients, J. Geophys. Res., 101, 1924519250, 1996.

Titos, G., Jefferson, A., Sheridan, P. J., Andrews, E., Lyamani, H., Alados-Arboledas, L., and Ogren, J. A.: Aerosol light-scattering enhancement due to water uptake during the TCAP campaign, Atmos. Chem. Phys., 14, 7031-7043, doi:10.5194/acp-14-70312014, 2014.

Tiwari, S., Payra, S., Mohan, M., Verma, S., and Bisht, D. S.: Visibility degradation during foggy period due to anthropogenic urban aerosol at Delhi, India, Atmospheric Pollution Research, 2, 116-120, 2011.

Trijonis, J. C., Malm, W. C., Pitchford, M., White, W. H., Charlson, R., Husar, R.: Visibility Existing and Historical Conditions - Causes and Effects, National Acid Precipitation Assessment Program (NAPAP), Washington, DC, Report 24, 1990. 
Venkataraman, C., Reddy, C. K., Josson, S., and Reddy, M. S.: Aerosol size and chemical characteristics at Mumbai, India, during the INDOEX-IFP (1999), Atmos. Environ., 36, 1979-1991, 2002.

Watson, J. and Chow, J.: Visibility and air pollution, WIT Transactions on Ecology and the Environment, 99, 5 pp., 2006.

Wilkins, E.: Air pollution and the London fog of December, 1952, Journal of the Royal Sanitary Institute, 74, 1-15, 1954.

Willett, K. M., Dunn, R. J. H., Thorne, P. W., Bell, S., de Podesta, M., Parker, D. E., Jones, P. D., and Williams Jr., C. N.: HadISDH land surface multi-variable humidity and temperature record for climate monitoring, Clim. Past, 10, 1983-2006, doi:10.5194/cp10-1983-2014, 2014.

Williams, M.: Air pollution and policy - 1952-2002, Sci. Total Environ., 334, 15-20, 2004.

WMO: International Meteorological Vocabulary, World Meteorological Organization, WMO-NO. 182, Geneva, Switzerland, 1992.
WMO: Guide to Meteorological Instruments and Methods of Observation, 7th edition, World Meteorological Organization, WMO-No. 8, Geneva Switzerland, 2008.

WMO: Manual on the Global Observing System, Volume I - Global Aspects, World Meteorological Organization, WMO-No. 544, Geneva, Switzerland, 2015.

Wu, D., Tie, X., Li, C., Ying, Z., Lau, A. K.-H., Huang, J., Deng, X., and Bi, X.: An extremely low visibility event over the Guangzhou region: A case study, Atmos. Environ., 39, 6568-6577, 2005.

Yang, L.-x., Wang, D.-c., Cheng, S.-h., Wang, Z., Zhou, Y., Zhou, X.-h., and Wang, W.-x.: Influence of meteorological conditions and particulate matter on visual range impairment in Jinan, China, Sci. Total Environ., 383, 164-173, 2007.

Zhang, Y.-h., Shao, M., and Cheng, C.-1.: Quantitative relationship between visibility and mass concentration of PM2. 5 in Beijing, J. Environ. Sci., 18, 475-481, 2006. 